\title{
Association Between Betaine Homocysteine S-Methyl Transferase (BHMT) rs3797546 Gene Polymorphisms and the Risk of Nonsyndromic Cleft Lip and/or Cleft Palate in South-East Population of Iran
}

\author{
Hooshang Rafighdoost ${ }^{1,2}$, Zahra Rafighdoost ${ }^{2}$, Mohsen Taheri ${ }^{3^{*}}$ \\ ${ }^{1}$ Cellular and Molecular Research Center, Zahedan University of Medical Sciences, Zahedan, IR Iran \\ ${ }^{2}$ Department of Anatomy, School of Medicine, Zahedan University of Medical Sciences, Zahedan, IR Iran \\ ${ }^{3}$ Genetics of Non Communicable Disease Research Center, Zahedan University of Medical Science, Zahedan, IR Iran
}

\section{A R T I C L E I N F O}

Article type:

Research Article

Article history:

Received: 30 Sep 2012

Revised: 02 Oct 2012

Accepted: 04 Oct 2012

Keywords:

Cleft Palate

Cleft Lip

Polymorphism

Single Nucleotide

\begin{abstract}
A B S T R A C T
Background: Nonsyndromic cleft lip with or without cleft palate (NS-CL/P) is one of the most common congenital anomalies and has a multifactorial etiology that involves both genetic and environmental factors.

Objectives: The present study was aimed to evaluate the possible association between BHMT rs3797546 gene polymorphisms and NS-CL/P in a sample of Iranian population.

Materials and Methods: This case-control study was performed on 100 NS-CL/P cases and 100 healthy controls. Tetra amplification refractory mutation system-polymerase chain reaction (T-ARMS-PCR) was used to detect the polymorphism. Analysis of data was done using $\chi^{2}$ test for categorical data, the associations between genotypes and NS-CL/P were estimated by computing the odds ratio (OR) and 95\% confidence intervals (95\% CI) from logistic regression analyses.

Results: No significant difference was found between the groups regarding BMHT rs3797546 gene polymorphism. The $C$ allele was not associated with NS-CL/P $(\mathrm{OR}=1.27$, $95 \% \mathrm{CI}=0.85-2.79, P=0.690)$.

Conclusions: Our data suggested that BMHT rs3797546 gene polymorphism was not associated with risk/ protection for NS-CL/P in a sample of Iranian population. Larger studies are required to validate our findings.
\end{abstract}

- Implication for health policy/practice/research/medical education:

The content and results of this paper is useful for researchers who are interested in genetic risk factor for predisposition to Nonsyndromic Cleft Lip and/or Cleft Palate.

\section{Please cite this paper as:}

Rafighdoost H, Rafighdoost Z, Taheri M. Association Between Betaine Homocysteine S-Methyl Transferase (BHMT) rs3797546 Gene Polymorphisms and the Risk of Nonsyndromic Cleft Lip and/or Cleft Palate in South-East Iranian Population. Health Scope. 2012; 1 (3): 144-6.

\footnotetext{
* Corresponding author: Mohsen Taheri, Genetics of Non Communicable Disease Research Center, Zahedan University of Medical Science, Zahedan, IR Iran, Tel: +54-13416703, Fax:+54-13416708,E-mail:amirt112@yahoo.com or taheri@zaums.ac.ir
} 


\section{Background}

Nonsyndromic cleft lip with or without cleft palate $(\mathrm{NCL} / \mathrm{P})$ is one the most common congenitally developmental disorder anomalies and the most frequent nonsyndromic orofacial cleft (1). The prevalence of CL/P varies widely by geographical origin, racial background, ethnic background, and socioeconomic status (2). The incidence of cleft lip and palate in Iran is approximately 1/1000 which is lower than other countries (3). CL/P is a complex defect determined by interaction between multiple genetic and environmental risk factors (4). Betaine-homocysteine s-methyl transferase (BHMT) gene encodes a cytosolic enzyme that catalyzes the conversion of betaine and homocysteine to dimethyl glycine and methionine, respectively. There is little and controversial information concerning the role of BHMT polymorphisms in susceptibility to $\mathrm{CL} / \mathrm{P}(5-8)$.

\section{Objectives}

Considering the crucial role played by this enzyme in methionine pathway, the current study was carried out to determine the impact of BHMT rs3797546 gene polymorphism on the risk of nonsyndromic cleft lip and/or cleft palate in a sample of Iranian population.

\section{Materials and Methods}

The study group consisted of $100 \mathrm{CL} / \mathrm{P}$ (61 males and 39 females) with an average age of $\mathbf{1 2 . 1 2}$ years (minimum 1 year, maximum 54 years) and 100 normal subjects (61 males and 39 females) with an average age of 12.03 years (minimum 1 year, maximum 51 years). All subjects were from Sistan and Baluchestan province. There was no significant difference between the groups regarding sex and age $(P>0.05)$. All participants were unrelated to each other. The local Ethics Committee of the Zahedan University of Medical Sciences approved the project, and written informed consent was taken from all participants. Blood samples were collected in Na-EDTA tubes from patients and healthy controls and stored at $-20{ }^{\circ} \mathrm{C}$ until DNA extraction. Genomic DNA extraction from blood samples was carried out as described previously (9). BHMT genomic sequence (NT_006713.15) was obtained from the National Center for Biotechnology Information (NCBI) (http:// www.ncbi.nlm.nih.gov). The polymorphism was searched and primers for T-ARMS-PCR, a simple and rapid method for detection of SNP (single nucleotide polymorphism), were designed (10-13) (Table 1). In T-ARMS-PCR method, two external primers (control band) and two inner primers (allele specific primers) were used. Polymerase chain reaction (PCR) was performed using commercially available PCR premix (AccuPower PCR Pre-Mix, BIONEER, Daejeon, South Korea) according to the manufacturer's recommended protocol. One $\mu \mathrm{L}$ of template DNA ( 100 ng/ $\mu \mathrm{L}), 1 \mu \mathrm{L}$ of each primer $(10 \mu \mathrm{M})$, and $15 \mu \mathrm{L}$ DNase-free water were added to a $0.2 \mathrm{~mL}$ PCR tube containing AccuPower PCR Pre-Mix. The PCR cycling condition for BHMT was 5 min at $95^{\circ} \mathrm{C}$ followed by 30 cycles of $30 \mathrm{~s}$ at $95^{\circ} \mathrm{C}, 30 \mathrm{~s}$ at 62 ${ }^{\circ} \mathrm{C}$, and $17 \mathrm{~s}$ at $72{ }^{\circ} \mathrm{C}$, with a final extension of $5 \mathrm{~min}$ at $72{ }^{\circ} \mathrm{C}$. The PCR products were analyzed by electrophoresis on a $2 \%$ agarose gel containing $0.5 \mu \mathrm{g} / \mathrm{mL}$ of ethidium bromide and visualized by trans-illumination with UV light, and photographs were taken (Figure 1).

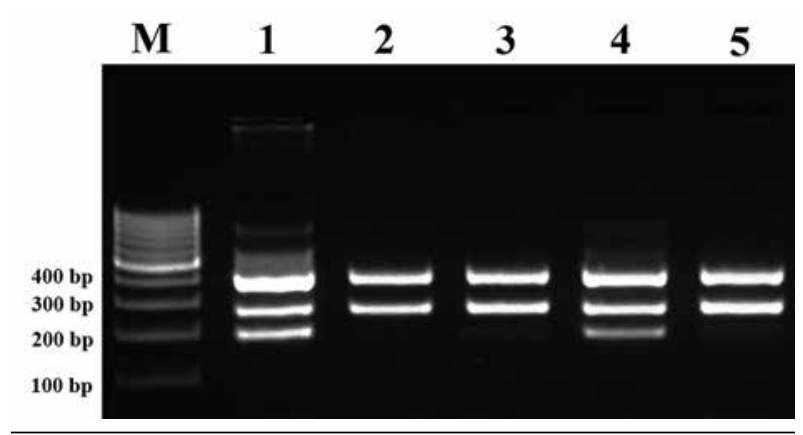

Figure 1. Photograph of the PCR Products of BMHT rs3797546 Gene Polymorphism

\subsection{Statistical Analysis}

The statistical analysis of data was performed using the SPSS 18.0 software. Demographic and biochemical parameters between the groups were analyzed by independent sample t-test for continuous data, and $\chi^{2}$ test for categorical data. The association between genotypes and NS-CL/P were estimated by computing the odds ratio (OR) and 95\% confidence intervals ( $95 \% \mathrm{CI}$ ) from logistic regression analyses adjusted for sex and age. In T-ARMS-PCR method, two external primers (control band) and two inner primers (allele specific primers) were used. The product sizes for detection of BHMT rs3797546 polymorphism were: 195 bp for C allele, $271 \mathrm{bp}$ for T allele, and $409 \mathrm{bp}$ for control band. M: DNA Marker; Lanes 1, 4: rs3797546 TC; Lanes 2, 3 , 5: rs3797546 TT.

\begin{tabular}{ll}
\hline \multicolumn{2}{l}{ Table 1. The Primers Used for Detection of BMHT rs3797546 Polymorphism } \\
\hline & Sequence $\left(\mathbf{5}^{\prime} \boldsymbol{}^{->} \mathbf{3}^{\prime}\right)$ \\
\hline FI (C allele) & AGAGATGAGTATAGACTCATCTCCAGCTTC \\
RI (T allele) & CACTGAAGTTCTTAGCTCTCAGCGATA \\
FO & AACAAGTTTGAAGCCCGCTAATTTAG \\
RO & AGGAGAATTAACTGGGCAAAGTAAGAAA \\
\hline
\end{tabular}

\section{Results}

The distribution of genotype and allele frequencies of BHMT rs3797546 gene polymorphism in NS-CL/P and healthy subjects are shown in Table 2. The wild-type genotype (TT) was observed in $85 \%$ of the patients, whereas $15 \%$ were heterozygous (TC). In the control group, the frequencies of genotypes were $88 \%$ for TT, and $12 \%$ for TC. There were no significant differences regarding BHMT 
rs3797546 polymorphism between NS-CL/P and healthy subjects $\left(\chi^{2}=0.38, P=0.535\right)$. No significant differences were observed among NS-CL/P and control subjects regarding allele frequencies $(P=0.690)$. The genotypes of BHMT rs3797546 polymorphism in cases and controls were in HWE (Hardy-weinberg equilibrium) $\left(\chi^{2}=0.66, P\right.$ $=0.417 ; \chi^{2}=0.41, P=0.523$, respectively).

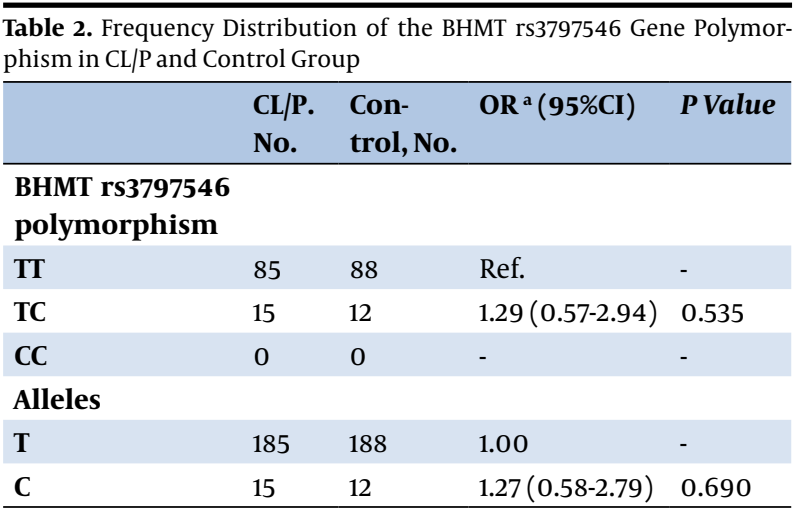

${ }^{\text {a Adjusted for sex and age }}$

\section{Discussion}

Though the CL/P etiology is mainly unknown, it has been proposed that both genetic and environmental factors contribute to the risk for NS-CL/P. In the present study, we examined DHMT rs3797546 gene polymorphism and susceptibility to $\mathrm{CL} / \mathrm{P}$ in a sample of Iranian population. The BHMT rs3797546 polymorphism was not associated with risk/protection for NS-CL/P in our population.

Few studies focused on BHMT polymorphisms as candidate markers for $\mathrm{CL} / \mathrm{P}$. Hu et al. (8) investigated BHMT rs651852, rs3797546, and rs3733890 gene polymorphisms. They found neither allelic nor genotypic associations between NS-CL/P and rs651852 as well as rs3733890 polymorphisms. In contrast to our findings, their findings showed that the rs3797546 polymorphism increased the risk for NS-CL/P in a recessive inheritance model $(P=$ 0.020, OR $=2.10,95 \% \mathrm{CI}=1.11-3.95 ; \mathrm{CC} v$ s. TT $+\mathrm{TC}$ ), while Martinelli et al. (5) found no significant association between BHMT and BHMT2 variants and CL/P. Mostowska et al. (14) reported that individuals with AA genotype of the BHMT rs3733890 polymorphism had a significantly lower risk for orofacial clefts. Zhu et al. (7) did not find any association between BHMT r239q as well as BHMT2 rs626105 polymorphisms and susceptibility to spina bifida or orofacial clefts. In conclusion, our data suggested that DHMT gene polymorphism was not associated with risk/protection for NS-CL/P in a sample of Iranian population. Larger studies with different ethnicities are required to confirm our findings.

\section{Acknowledgments}

None declared.

\section{Authors' Contribution}

All authors have made extensive contribution into design of the study, data collection, analysis and interpretation of the data, drafting and final approval the manuscript.

\section{Financial Disclosure}

None declared.

\section{Funding/Support}

None declared.

\section{References}

1. Mossey PA, Little J, Munger RG, Dixon MJ, Shaw WC. Cleft lip and palate. Lancet. 2009;374(9703):1773-85.

2. Dixon MJ, Marazita ML, Beaty TH, Murray JC. Cleft lip and palate: understanding genetic and environmental influences. Nat Rev Genet. 2011;12(3):167-78.

3. Khazaei S, Shirani AM, Khazaei M, Najafi F. Incidence of cleft lip and palate in Iran. A meta-analysis. Saudi Med J. 2011;32(4):390-3.

4. Lidral AC, Moreno LM. Progress toward discerning the genetics of cleft lip. Current opinion ped. 2005;17(6):731-9.

5. Martinelli M, Masiero E, Carinci F, Morselli PG, Pezzetti F, Scapoli L. New evidence for the role of cystathionine beta-synthase in non-syndromic cleft lip with or without cleft palate. Eur J Oral Sci. 2011;119(3):193-7.

6. Mostowska A, Hozyasz KK, Biedziak B, Misiak J, Jagodzinski PP Polymorphisms located in the region containing BHMT and BHMT2 genes as maternal protective factors for orofacial clefts. Eur J Oral Sci. 2010;118(4):325-32.

7. Zhu H, Curry S, Wen S, Wicker NJ, Shaw GM, Lammer EJ, et al. Are the betaine-homocysteine methyltransferase (BHMT and BHMT2) genes risk factors for spina bifida and orofacial clefts? Am J Med Genet A. 2005;135(3):274-7.

8. Hu Y, Chen E, Mu Y, Li J, Chen R. BHMT gene polymorphisms as risk factors for cleft lip and cleft palate in a Chinese population. Biomed Environ Sci. 2011;24(2):89-93.

9. Hashemi M, Moazeni-Roodi AK, Fazaeli A, Sandoughi M, Bardestani GR, Kordi-Tamandani DM, et al. Lack of association between paraoxonase-1 Q192R polymorphism and rheumatoid arthritis in southeast Iran. Genet Mol Res. 2010;9(1):333-9.

10. Hashemi M, Moazeni-Roodi A, Bahari A, Taheri M. A tetra-primer amplification refractory mutation system-polymerase chain reaction for the detection of rs8099917 IL28B genotype. Nucleoside Nucle Acid. 2012;31(1):55-60.

11. Hashemi M, Moazeni-Roodi AK, Fazaeli A, Sandoughi M, Taheri M, Bardestani GR, et al. The L55M polymorphism of paraoxonase-1 is a risk factor for rheumatoid arthritis. Genet Mol Res. 2010;9(3):1735-41.

12. Hashemi M, Hoseini H, Yaghmaei P, Moazeni-Roodi A, Bahari A, Hashemzehi N, et al. Association of polymorphisms in glutamate-cysteine ligase catalytic subunit and microsomal triglyceride transfer protein genes with nonalcoholic fatty liver disease. DNA Cell Biol. 2011;30(8):569-75.

13. Hashemi M, Eskandari-Nasab E, Fazaeli A, Bahari A, Hashemzehi NA, Shafieipour S, et al. Association of genetic polymorphisms of glutathione-S-transferase genes (GSTT1, GSTM1, and GSTP1) and susceptibility to nonalcoholic fatty liver disease in Zahedan, Southeast Iran. DNA Cell Biol. 2012;31(5):672-7.

14. Mostowska A, Hozyasz KK, Wojcicki P, Dziegelewska M, Jagodzinski PP. Associations of folate and choline metabolism gene polymorphisms with orofacial clefts. J Med Genet. 2010;47(12):809-15. 